\title{
Herbicidas utilizados em milho no controle de soja voluntária
}

\author{
Herbicides used in corn in control of voluntary soybeans \\ José Gabriel Castilho Theodoro', Guilherme Mendes Pio de Oliveira²*, \\ Éllen Stephanny Tanaka dos Santos ${ }^{1}$, Fernanda Neves Paduan ${ }^{2}$, Rubiane Pellozo Alberti ${ }^{1}$, \\ Luis Gustavo Lofrano ${ }^{1}$, Jethro Barros Osipe ${ }^{1}$
}

Resumo - A soja voluntária é um problema no cultivo do milho, interferindo em seu desenvolvimento e crescimento. O objetivo do trabalho foi avaliar a eficiência de herbicidas utilizados na cultura do milho para o controle de plantas de soja voluntária em dois estádios fenológicos. $\mathrm{O}$ experimento foi conduzido em casa de vegetação, em delineamento experimental inteiramente casualizado, em esquema fatorial $2 \times 11$, tendo como fatores dois estádios fenológicos e onze caldas de herbicidas, com quatro repetições. As caldas testadas foram compostas por: nicosulfuron (40 $\mathrm{g} \mathrm{ha}^{-1}$ i.a. $)$; tembotrione (75 $\mathrm{g} \mathrm{ha}^{-1}$ i.a.); mesotrione (480 $\mathrm{g} \mathrm{ha}^{-1}$ i.a.); atrazine (500 $\mathrm{g} \mathrm{ha}^{-1}$ i.a.); 2,4-D (806 $\mathrm{g} \mathrm{ha}^{-1}$ i.a.); dicamba (480 $\mathrm{g} \mathrm{ha}^{-1}$ e.a.); glufosinato de amônio (200 $\mathrm{g} \mathrm{ha}^{-1}$ i.a.); atrazine + tembotrione $\left(500+75 \mathrm{~g} \mathrm{ha}^{-1}\right.$ i.a.); atrazine + mesotrione $\left(500+480 \mathrm{~g} \mathrm{ha}^{-1}\right.$ i.a. $)$; atrazine + nicosulfuron $\left(500+40 \mathrm{~g}^{-1}\right.$ i.a. $)$, além da testemunha sem aplicação. Foram realizadas avaliações visuais aos 07, 14, 21, 28 e 35 dias após aplicação (DAA) para determinar o controle da soja voluntária. Os resultados indicam que em ambos estádios fenológicos, os herbicidas mesotrione, nicosulfuron, tembotrione e 2,4-D não apresentaram controle total da soja. Glufosinato de amônio, atrazine isolada ou associada ao mesotrione, nicosulfuron e tembotrione controlaram $100 \%$ as plantas de soja, a partir dos 7 DAA. Dicamba apresentou controle total, no estádio fenológico V1 e V3, a partir de 7 DAA e 14 DAA, respectivamente.

Palavras-chave: competição, Glycine max L., mistura de herbicidas, Zea mays L

Abstract - Volunteer soy is a problem in maize cultivation, interfering with its development and growth. The objective of this work was to evaluate the efficiency of herbicides used in maize for the control of volunteer soybean plants in two phenological stages. The experiment was conducted in a greenhouse, in a completely randomized experimental design in factorial $2 \times 11$, having as factors two phenological stages and eleven herbicides spray, with four replications. The herbicides spray were composed by: nicosulfuron (40 g ha-1 i.a.); tembotrione (75 g ha-1 i.a.); mesotrione (480 g ha-1 a.i.); atrazine (500 g ha-1 a.i.); 2.4-D (806 g ha-1 a.i.); dicamba (480 g ha-1 a.e.); glufosinate-ammonium (200 g ha-1 a.i.); atrazine + Tembotrione $(500+75$ g ha-1 i.a. $)$; atrazine + mesotrione $(500+480 \mathrm{~g}$ ha- 1 a.i. $)$; atrazine + nicosulfuron $(500+40 \mathrm{~g}$ ha-1 i.a. $)$, in addition to a control without application. Visual evaluations were realized at 07, 14, 21, 28 and 35 (DAA) days after application,

Recebido: Agosto 08, 2018. Aceito: Fevereiro 01, 2019.

${ }^{1}$ Departamento de Engenharia e Desenvolvimento Agrário, Universidade Estadual do Norte do Paraná - UENP, Bandeirantes, PR, Brasil. E-mail: jgtheodoro@gmail.com; fannytanaka@outlook.com; rubiane_pelozzo@yahoo.com.br; gustavo_lofrano1@hotmail.com; jethrosipe@gmail.com

${ }^{2}$ Universidade Estadual de Londrina - UEL, Rodovia Celso Garcia Cid, PR-445, Km 380, CEP 86055-900, Londrina, PR, Brasil. E-mail: guilhermemendespio@gmail.com; f.paduan@hotmail.com 
to determine the control of the voluntary soybean. The results indicate that in both phenological stages, the herbicides mesotrione, nicosulfuron, tembotrione and 2,4-D did not present total control of the soybean. Glufosinate ammonium, atrazine isolated or associated with mesotrione, nicosulfuron and tembotrione $100 \%$ controlled the soybean plants from 7 DAA. Dicamba presented total control, in the phenological stage V1 and V3, from 7 DAA and 14 DAA, respectively.

Keywords: competition, Glycine max L, herbicide mixture, Zea mays L

\section{Introdução}

A sucessão soja e milho safrinha predomina nas áreas de cultivo de cereais do território brasileiro. Nesse sistema, o milho é semeado logo após a colheita da soja, enquanto que a semeadura da soja ocorre entre um a quatro meses após a colheita do milho. A perda de grãos é fator comumente observado na operação de colheita mecanizada, que ao germinarem originam as plantas voluntárias, infestantes da cultura em sucessão (Petter et al., 2016) podendo interferir na produtividade e qualidade da rotação ou sistema de sucessão na cultura do milho (Marquardt et al., 2012).

Segundo Adegas et al. (2014) populações de até quatro plantas de soja por $\mathrm{m}^{2}$ não provocaram diferenças significativas na produtividade do milho safrinha, sendo que a partir de 8,16 e 32 plantas por $\mathrm{m}^{2}$, houve redução da mesma em 14\%, 25\% e 40\%, respectivamente. Além de perdas na produtividade, a ocorrência dessas plantas na entressafra torna-se fonte de inóculo de fungos causadores de doenças, tal como a ferrugem asiática da soja (Phakopsora pachyrhizi) (Terasawa et al., 2009).

A sensibilidade da soja voluntária aos herbicidas é influenciada pelo estádio fenológio em que as plantas se encontram. Quanto mais avançado o estádio de desenvolvimento das plantas, maior a tolerância a estes, como observado para herbicidas inibidores da acetolactato síntese (ALS) (Braz et al., 2013).

No manejo de plantas voluntárias, tem-se os cuidados durante a operação de colheita e o uso de produtos fitossanitários, sendo o herbicida glyphosate comumente utilizado. No entanto, com o advento da soja Roundup Ready (RR) impossibilitou o controle da soja voluntária em milho com este herbicida, tornando-se um problema para países que adotam essa tecnologia (Adegas et al., 2009) em função de ambas culturas apresentarem cultivares que promovem tolerância ao glyphosate.

Com a adoção de novas tecnologias de soja transgênicas, tais como, Liberty Link, Enlist e Xtend que possuem resistência a mais de uma molécula de herbicida, tende a aumentar a ocorrência de soja voluntária na cultura do milho (Scott, 2014), uma vez que determinados herbicidas utilizados na dessecação e pós-emergência não controla a mesma (Petter et al., 2016) logo, as opções para o manejo químico podem ser limitadas (Marquardt et al., 2013).

Estudos são necessários a fim de encontrar alternativas para o controle das plantas de soja voluntárias, assim, o objetivo do estudo foi avaliar a eficiência de herbicidas utilizados na cultura do milho no controle de plantas de soja voluntária em dois estádios fenológicos.

\section{Material e métodos}

O experimento foi conduzido no período de abril a junho de 2017. O delineamento experimental utilizado foi o inteiramente casualizado, em esquema fatorial $2 \times 11$, sendo o primeiro fator composto pelos estádios fenológicos e o segundo fator composto pelas caldas de herbicidas, sendo realizadas quatro repetições. O solo utilizado foi peneirado e alocado em vasos plásticos com capacidade de $5 \mathrm{dm}^{3}$, que se constituíram como unidades experimentais. O solo foi classificado como Latossolo Vermelho Eutroférrico (Embrapa, 2013), cujas características físico-químicas são descritas na Tabela 1.

Foram semeadas cinco sementes do cultivar de soja potência 5D6215 RR por unidade experimental, em profundidade de $0,04 \mathrm{~m}$, previamente tratadas com piraclostrobina + tiofanato metílico + fipronil 
na dose recomendada. Aos cinco dias após a emergência realizou-se o desbaste, mantendo duas plantas por vaso, cujos mesmos foram irrigados diariamente conforme a necessidade hídrica das plantas.

$\mathrm{O}$ fator de tratamento constou de diferentes herbicidas, totalizando onze níveis, cujos tratamentos utilizados são descritos na Tabela 2. A aplicação dos tratamentos nos diferentes experimentos foi realizada quando as plantas se apresentavam em estádio vegetativo V1 e V3, aos 18 e 32 dias após a semeadura, respectivamente.

Para as aplicações dos tratamentos foi utilizado pulverizador costal pressurizado com $\mathrm{CO}_{2}$, equipado com quatro pontas do tipo XR 110.02 espaçadas em $0,5 \mathrm{~m}$ entre si e posicionadas $0,5 \mathrm{~m}$ da superfície dos alvos, com pressão de trabalho de $310,26 \mathrm{kPa}$, calibrado para a taxa de aplicação correspondente a $150 \mathrm{~L} \mathrm{ha}^{-1}$. No momento das aplicações, a velocidade do vento foi de 1,3 a 2,3 $\mathrm{m} \mathrm{s}^{-1}$, a temperatura do ar de 27,3 a $28,5^{\circ} \mathrm{C}$ e umidade relativa do ar de 49 a $53 \%$.

A avaliação do controle das plantas de soja foi realizada de forma visual aos 7 e 14, 21, 28 e 35 dias após a aplicação (DAA), em escala percentual em que zero e cem representam ausência de injúrias e morte das plantas, respectivamente (SBCPD, 1995). Os dados coletados foram submetidos à análise de variância e em constatada significância, as médias de controle proporcionadas pelas caldas foram comparadas pelo teste de Scott-Knott a 5\% de significância.

\section{Resultados e discussão}

Os resultados médios de controle de plantas de soja no estádio fenológico V1 e V3 estão expressos nas Figuras 1 a 5. Os herbicidas

Tabela 1. Análise química e granulométrica do Latossolo Vermelho.

\begin{tabular}{|c|c|c|c|c|c|c|c|c|c|c|c|}
\hline \multirow{2}{*}{$\begin{array}{c}\text { Prof } \\
\mathrm{cm}\end{array}$} & \multirow{2}{*}{$\frac{\mathrm{pH}}{\mathrm{CaCl}}$} & \multirow{2}{*}{$\frac{\text { M.O }}{\mathrm{g} \mathrm{dm}^{-3}}$} & $\mathbf{P}$ & $\mathbf{K}$ & $\mathbf{C a}$ & Mg & Al & $\mathbf{H}+\mathbf{A l}$ & SB & CTC & V\% \\
\hline & & & \multicolumn{2}{|c|}{$\mathrm{mg} \mathrm{dm}^{-3}$} & \multicolumn{7}{|c|}{ - } \\
\hline 0-20 & 5,6 & 13,4 & 24,7 & 0,64 & 0,84 & 2,60 & $\mathbf{0 , 0}$ & 3,19 & 11,64 & 14,83 & $\mathbf{7 8 , 5}$ \\
\hline & & & & & $\begin{array}{r}\text { Granul } \\
\mathrm{A}\end{array}$ & $\begin{array}{l}\text { tria }(\% \\
\text { LA }\end{array}$ & & & & & \\
\hline
\end{tabular}

Tabela 2. Descrição dos tratamentos herbicidas utilizados nos experimentos testando eficiência de controle de soja voluntária em diferentes estádios fenológicos. Bandeirantes-PR, 2017.

\begin{tabular}{|c|c|c|c|}
\hline Tratamentos & Mecanismos de ação & Concentração (g L L i.a.) & Dose ( $\mathrm{g} \mathrm{ha}^{-1}$ i.a.) \\
\hline Nicosulfuron & Inibidor de ALS & 40,0 & 60,0 \\
\hline Tembotrione $^{*}$ & Inibidor de HPPD & 75,0 & 13,5 \\
\hline Mesotrione & Inibidor de HPPD & 480,0 & 192,0 \\
\hline Atrazine* & Inibidor de fotossistema II & 500,0 & 1500,0 \\
\hline $2,4-\mathrm{D}$ & Mimetizador de auxina & 806,0 & 806,0 \\
\hline Dicamba & Mimetizador de auxina & 480,0 & 480,0 \\
\hline Glufosinato de amônio** & Inibidor da GS & 200,0 & 600,0 \\
\hline Atrazine + Tembotrione* & $\begin{array}{l}\text { Inibidor do Fotossistema II + } \\
\text { Inibidor de HPPD }\end{array}$ & $500,0+75,0$ & $1500,0+13,5$ \\
\hline Atrazine + Mesotrione* & $\begin{array}{l}\text { Inibidor do Fotossistema II + } \\
\text { Inibidor de HPPD }\end{array}$ & $500,0+480,0$ & $1500,0+192,0$ \\
\hline Atrazine + Nicosulfuron* & $\begin{array}{l}\text { Inibidor do Fotossistema II + } \\
\text { Inibidor de ALS }\end{array}$ & $500,0+40,0$ & $1500,0+60,0$ \\
\hline Testemunha sem aplicação & - & - & - \\
\hline
\end{tabular}




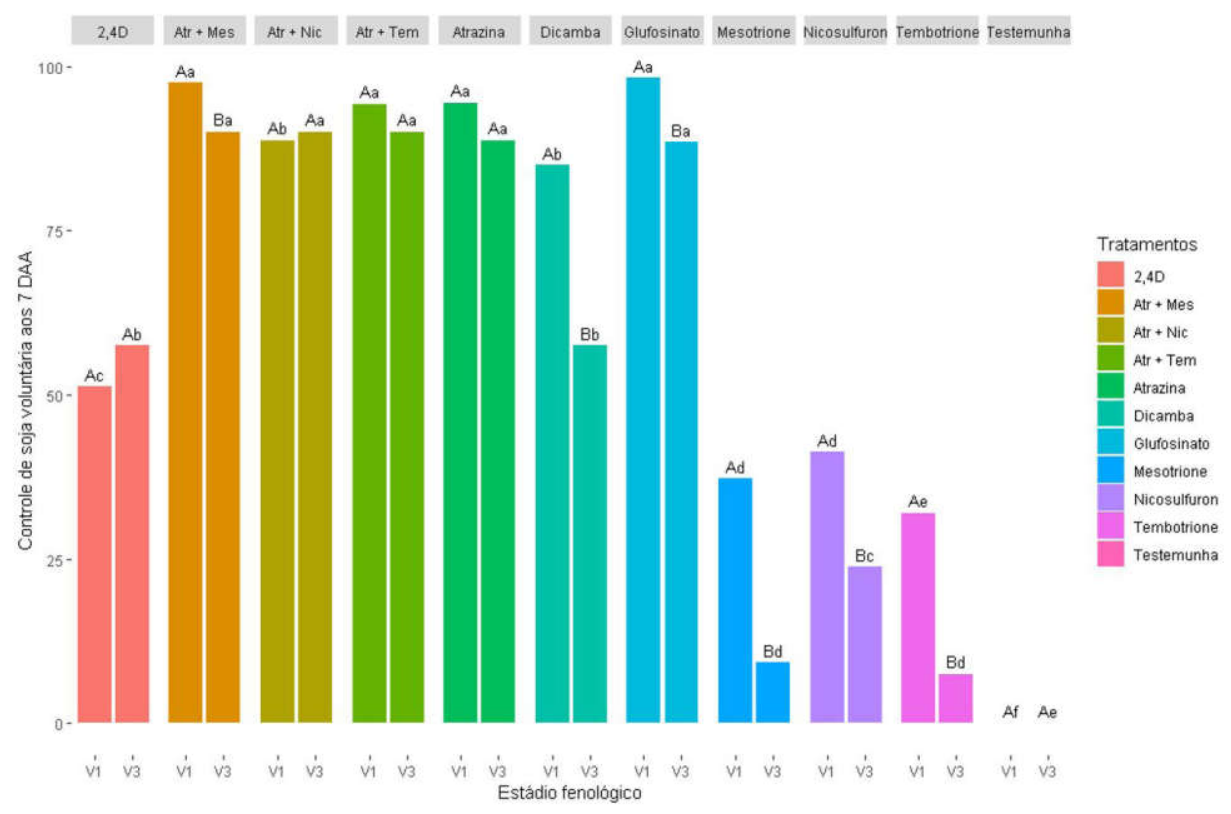

Figura 1. Porcentagem de controle de soja voluntária nos estádios fenológicos V1 e V3 aos 7 dias após a aplicação.

Letras maiúsculas representam a análise estatística do Teste de Scott-Knott a 5\% para estádios fenológicos. Letras minúsculas representam a análise estatística do Teste de Scott-Knott a 5\% para herbicidas.

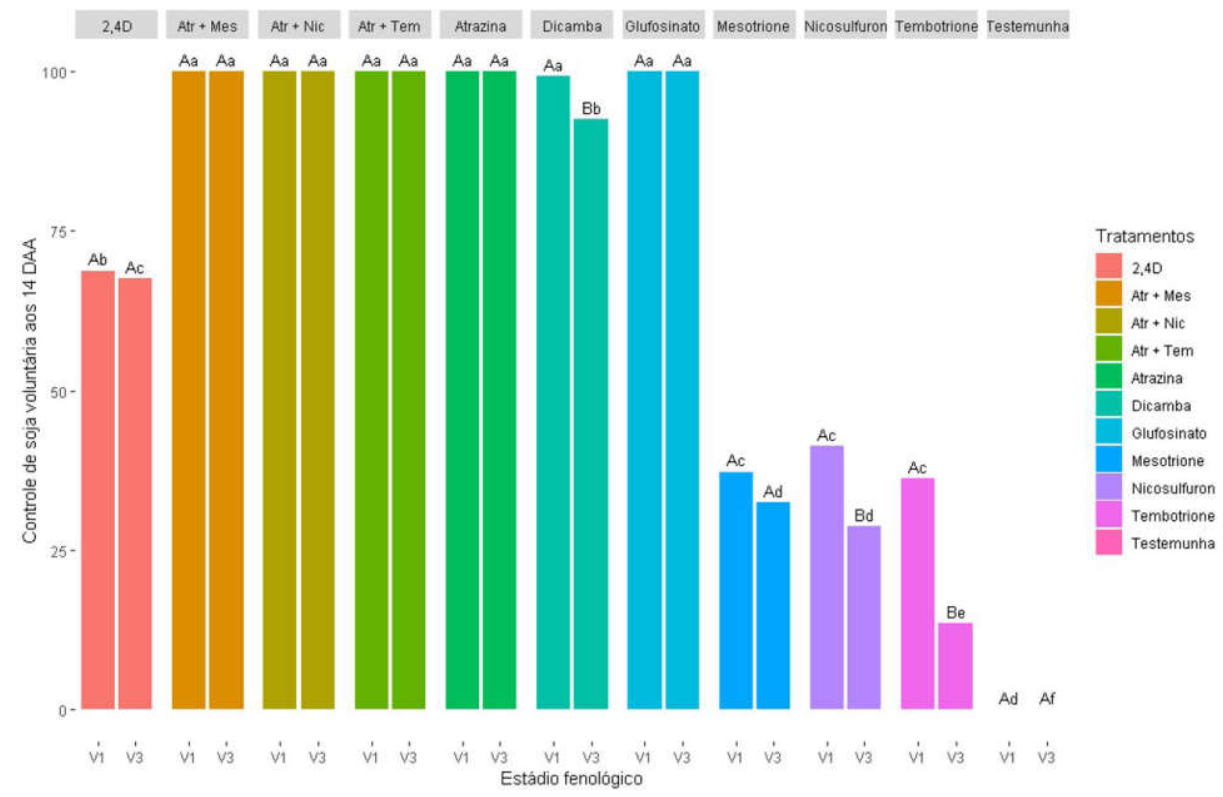

Figura 2. Porcentagem de controle de soja voluntária nos estádios fenológicos V1 e V3 aos 14 dias após a aplicação.

Letras maiúsculas representam a análise estatística do Teste de Scott-Knott a 5\% para estádios fenológicos. Letras minúsculas representam a análise estatística do Teste de Scott-Knott a 5\% para herbicidas. 


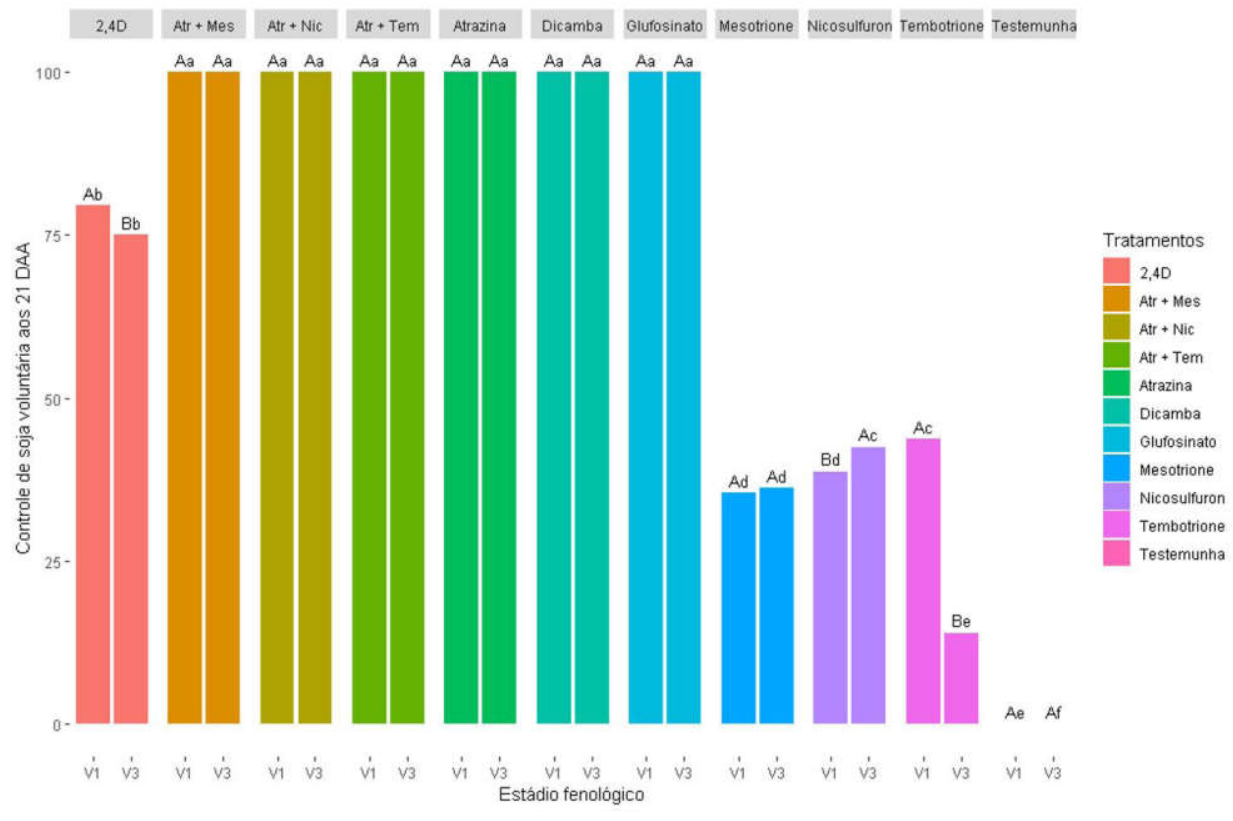

Figura 3. Porcentagem de controle de soja voluntária nos estádios fenológicos V1 e V3 aos 21 dias após a aplicação.

Letras maiúsculas representam a análise estatística do Teste de Scott-Knott a 5\% para estádios fenológicos. Letras minúsculas representam a análise estatística do Teste de Scott-Knott a 5\% para herbicidas.

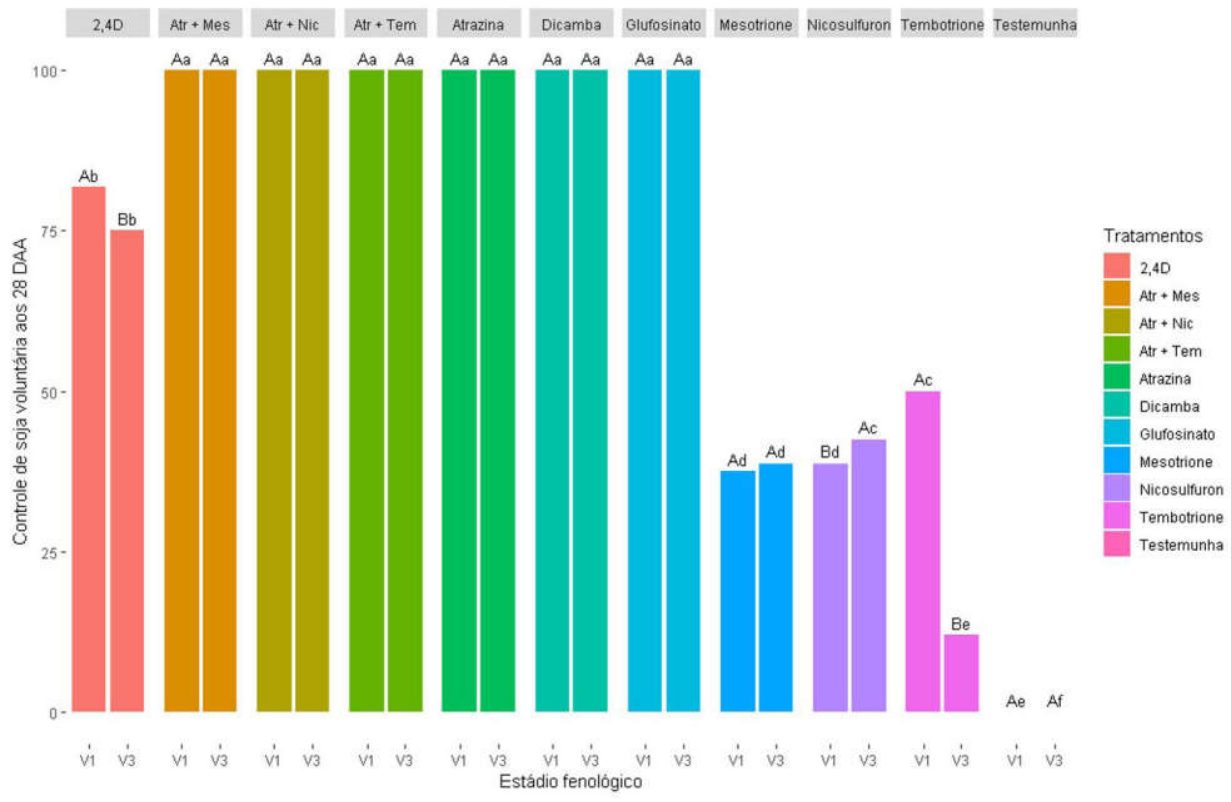

Figura 4. Porcentagem de controle de soja voluntária nos estádios fenológicos V1 e V3 aos 28 dias após a aplicação.

Letras maiúsculas representam a análise estatística do Teste de Scott-Knott a 5\% para estádios fenológicos. Letras minúsculas representam a análise estatística do Teste de Scott-Knott a 5\% para herbicidas. 


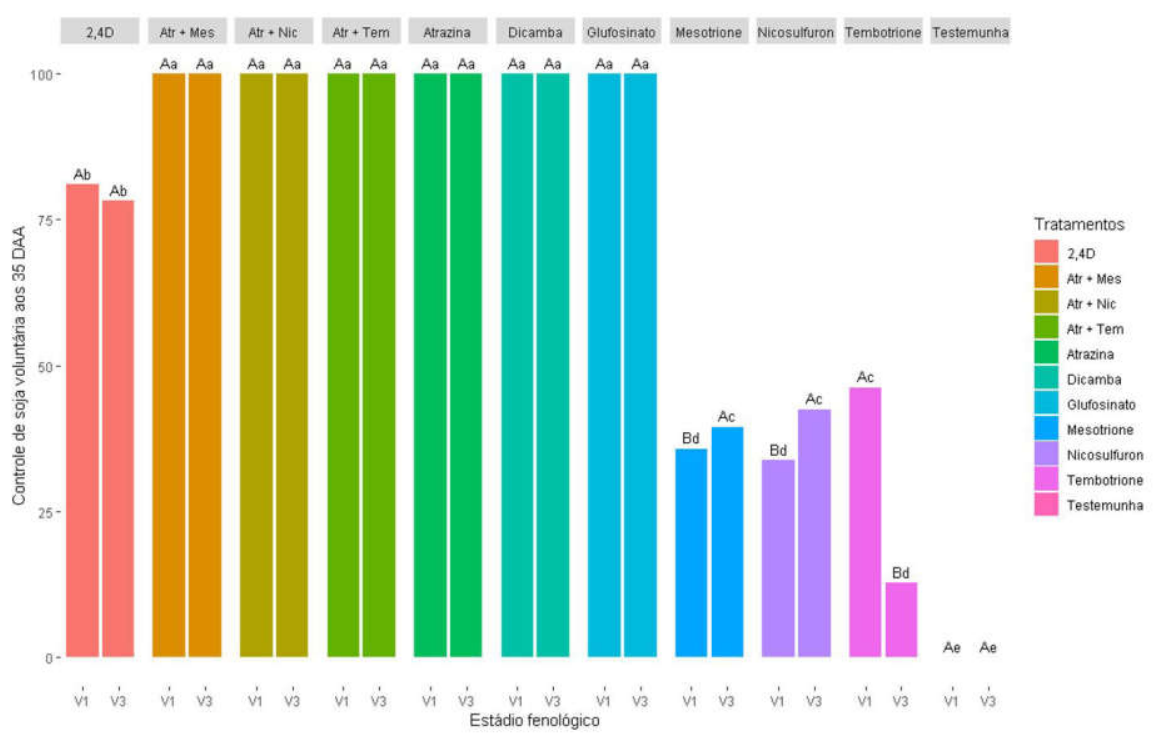

Figura 5. Porcentagem de controle de soja voluntária nos estádios fenológicos V1 e V3 aos 35 dias após a aplicação.

Letras maiúsculas representam a análise estatística do Teste de Scott-Knott a 5\% para estádios fenológicos. Letras minúsculas representam a análise estatística do Teste de Scott-Knott a 5\% para herbicidas.

isolados nicosulfuron, tembotrione e mesotrione não controlaram totalmente a soja voluntária, apresentando o menor controle entre todas as caldas independente da época de avaliação (Figuras 1 a 5), podendo ser justificado pelo fato de esses herbicidas serem recomendados, principalmente, para o controle de monocotiledôneas. Atrazine isolada ou associada, glufosinato de amônio e dicamba foram superiores aos demais herbicidas, em ambos estádios fenológicos, exceto o dicamba aos 7 DAA que não diferiu de 2,4-D quando avaliado em V3.

Dan et al. (2011a) relataram controle acima de $95 \%$ de soja voluntária no estádio V3, utilizando atrazine (1500 $\mathrm{g} \mathrm{ha}^{-1}$ i.a.). No entanto, constataram controle insatisfatório, utilizando os herbicidas mesotrione e tembotrione (Dan et al., 2011b).

Nas caldas compostas pela associação de atrazine aos herbicidas nicosulfuron, tembotrione $\mathrm{e}$ mesotrione houve maior controle quando comparado com a aplicação de forma isolada dos mesmos. Resultados semelhantes foram observados por Grigolli et al. (2017) onde a adição de atrazine ao herbicida nicosulfuron, controlou $100 \%$ das plantas de soja, enquanto que na ausência da atrazine, o controle foi abaixo de $30 \%$.

Essa associação dos herbicidas do grupo químico das triazinas, que inibe a fotossíntese no Fotossistema II, a outros mecanismos de ação, tais como o grupo químico das cloroacetamidas que inibem o crescimento inicial e o grupo químico das sulfoniluréias, que inibem a síntese de acetolactato visa a ampliação do espectro de controle de plantas daninhas mono e eudicotiledôneas (Dan et al., 2011b; Vargas et al., 2006), além de contribuir na prevenção do surgimento de biótipos resistentes (Belapart et al., 2013).

Por ser um herbicida de contato e de ação rápida, a atrazine impossibilita o transporte de elétrons até a plastoquinona, não permitindo a produção de ATP (energia), resultando na formação de espécies reativas de oxigênio que rapidamente destroem as membranas de organelas e plasmalema (Summers, 1980).

O herbicida glufosinato de amônio e atrazine + mesotrione obtiveram controle satisfatório 
independente da época avaliada, no entanto, observou-se influência do estádio fenológico aos 7 DAA. De acordo com Braz et al. (2013), o uso de glufosinato de amônio em V1 proporcionaram controle total de plantas de soja voluntária.

Observou-se controle total quando aplicado dicamba no estádio fenológico V1 e V3, a partir de 7 DAA e 14 DAA, respectivamente. As lesões causadas pelo mesmo, prejudicam o equilíbrio hormonal e interferem no crescimento e desenvolvimento de plantas de soja, resultando em epinastia e folhas distorcidas. Esses efeitos são constatados, principalmente quando esse herbicida é utilizado na cultura do milho para controle de soja voluntária (Kelley et al., 2017).

O herbicida 2,4-D ocasionou prejuízo foliar severo, afetando o desenvolvimento das plantas, tendo a influência do estádio fenológico, no entanto não apresentou controle total. A auxina sintética (2,4-D) não é metabolizada tão rapidamente quanto a auxina endógena em eudicotiledôneas (Taiz et al., 2017). O 2,4-D, provoca ocorrência de epinastia e encarquilhamento de folhas e tecidos em plantas de soja (Silva et al., 2011).

Entre os mimetizadores de auxina, o herbicida dicamba causou maior injúria quando comparado ao 2,4-D, em ambos estádios fenológicos, exceto aos 7 DAA que não diferiu de 2,4-D quando avaliado em V3. Em geral, o dicamba é mais prejudicial à cultura da soja que o 2,4-D (Solomon e Bradley, 2014) sendo a diferença na magnitude do controle explicada pela sensibilidade da espécie, que apresenta variação na taxa de metabolização de acordo com o herbicida. Resultados semelhantes foram encontrados por Johnson et al. (2012) e Silva et al. (2018) que observaram maior fitotoxicidade do herbicida dicamba na soja quando comparado ao 2,4-D.

Os herbicidas dicamba, glufosinato de amônio e atrazine, possuem mecanismos de ação diferentes e se mostraram como alternativa no controle da soja voluntária. A rotação de mecanismos de ação é importante para evitar a seleção de plantas voluntárias resistentes em área de cultivo (Petter et al., 2016).

Em áreas de cultivo que apresentarem plantas de soja voluntária LL (Liberty Link) resistente ao glufosinato de amônio, tem-se como alternativa de controle o uso de atrazine e dicamba, ou o 2,4-D em estádio inicial. A soja Enlist resistente ao 2,4-D, glyphosate e glufosinato de amônio, possui como alternativa os herbicidas atrazine e dicamba. A soja Xtend resistente ao glyphosate e dicamba apresenta-se como alternativa atrazine e $2,4-\mathrm{D}$.

\section{Conclusão}

Em ambos estádios fenológicos, os herbicidas mesotrione, nicosulfuron, tembotrione e 2,4-D não apresentaram controle eficiente da soja.

Glufosinato de amônio, atrazine isolada ou associada ao mesotrione, nicosulfuron e tembotrione controlaram $100 \%$ das plantas de soja, a partir dos 7 DAA.

O herbicida dicamba apresentou controle total, no estádio fenológico V1 e V3, a partir de 7 DAA e 14 DAA, respectivamente.

\section{Referências}

Adegas, F.S.; Gazziero, D.L.; Voll, E. Interferência da infestação de plantas voluntárias no sistema de produção com a sucessão soja e milho safrinha. Londrina: Embrapa Soja, 2014. Disponível em: $<$ http://seer.sct.embrapa.br/index.php/pab/article/ view/21719>. Acesso em: 02 dez. 2018.

Adegas, F.S.; Gazziero, D.L.; Voll, E. Plantio Direto: cuidados na colheita reduzem plantas voluntárias de plantas transgênicas. Revista Visão Agrícola, v.9, n.8, p.126-129, 2009.

Belapart, D.; Marchesi, B.B.; Girotto, M.; Tropaldi, L.; Castro, E.B. Eficiência fotossintética de misturas de herbicidas no controle de Ipomoea grandifolia. Revista Científica Eletrônica de Agronomia, v.24, p.102-109, 2013. 
Braz, G.B.P.; Oliveira Junior, R.S.; Constantin, J.; Neto, A.M.O.; Dan, H.A.; Guerra, N.; et al. Alternativas para o controle de soja RR ${ }^{\circledR}$ voluntária na cultura do algodoeiro. Bioscience Journal, v.29, n.2, p.360-369, 2013.

Dan, H.A.; Dan, L.G.M.; Barroso, A.L.L.; Oliveira Junior, R.S.; Neto, A.M.O. Supressão imposta pelo atrazine a Digitaria horizontalis em função do estádio de desenvolvimento. Revista Caatinga, v.24, n.1, p.27-33, 2011 b.

Dan, H.A.; Procópio, S.O.; Barroso, A.L.; Dan, L.G.M.; Oliveira Neto, A.M.; Guerra, N. Controle de plantas voluntárias de soja com herbicidas utilizados em milho. Agrária, v.6, n.2, p.253257, 2011a.

EMBRAPA. Centro Nacional de Pesquisa de Solos. Sistema Brasileiro de Classificação de Solos. Brasília: Embrapa, 2013. 353p.

Grigolli, J.F.J.; Gitti, D.C.; Lourenção, A.L.F. Controle de plantas de soja e supressão do capim em milho consorciado com Brachiaria ruziziensis. Plant Science, v. 84, n.1, p.1-7, 2017.

Johnson, V.A.; Fisher, L.R.; Jordan, D.L.; Edmisten, K.E.; Stewart, A.M.; York, A.C. Cotton, peanut, and soybean response to sublethal rates of dicamba, glufosinate, and 2,4-D. Weed Technology, v.26, n.2, p.195-206, 2012.

Kelley, K.B.; Riechers, D.E.; Nordby, D.; Hager, A.G. Plant growth regulator injury to soybean. 2017. Disponível em: $<\mathrm{http}$ //weeds.cropsci.illinois. edu/extension/factsheets/PGR.pdf $>$. Acesso em: 18 abr. 2018.

Marquardt, P.T.; Terry, R.M.; Johnson, W.G. The impact of volunteer corn on crop yields and insect resistance management strategies. Agronomy (Basel), v.3, n.3, p.488-496, 2013.

Marquardt, P.T.; Terry, R.M.; Krupke, C.H.; Johnson, W.G. Competitive effects of volunteer corn on hybrid corn growth and yield. Weed Science, v.60, n.4, p.537-541, 2012.
Petter, F.A.; Pacheco, L.P.; Silva, A.F.; Morais, L.A. Management of volunteer plants in cultivation systems of soybeans, corn and cotton resistant to glyphosate. Revista Brasileira de Herbicidas, v.15, n.1, p.58-66, 2016.

SBCPD - Sociedade Brasileira da Ciência das Plantas Daninhas. Procedimentos para instalação, avaliação e análise de experimentos com herbicidas. Londrina: SBCPD, 1995. 42p.

Scott, B. HPPD Herbicide-Tolerant Soybeans:

New Type of GMO. Delta Farm Press, 2014.

Disponível em: <https://www.farmprogress.com/ soybeans/hppd-herbicide-tolerant-soybeans-newtype-gmo $>$. Acesso em: 05 jun. 2018.

Silva, D.R.O.; Silva, E.D.N.; Aguiar, A.C.M.; Novello, B.D.P.; Silva, A.A.A.; Basso, C.J. Drift of 2,4-D and dicamba applied to soybean at vegetative and reproductive growth stage. Ciência Rural, v.48, n.8, 2018.

Silva, F.M.L.; Cavalieri, S.D.; José, A.R.S.; Ulloa, S.M.; Velini, E.D. Atividade residual de 2,4-D sobre a emergência de soja em solos com texturas distintas. Revista Brasileira de Herbicidas, v.10, n.1, p.29-36, 2011.

Solomon, C.B.; Bradley, K.W. Influence of application timings and sublethal rates of synthetic auxin herbicides on soybean. Weed Technology, v.28, n.3, p.454-464, 2014.

Summers, L.A. The bipyridinium herbicides. New York: Academy Press, 1980. 449p.

Taiz, L.; Zeiger, E.; Møller, I.M.; Murphy, A. Fisiologia e desenvolvimento vegetal. 6.ed. Porto Alegre: Artmed, 2017. 888p.

Terasawa, J.M.; Panobianco, M.; Possamai, E.; Koehler, H.S. Antecipação da colheita na qualidade fisiológica de sementes de soja. Bragantia, v.68, n.3, p.765-773, 2009.

Vargas, L.; Peixoto, C.M.; Roman, E.S. Manejo de plantas daninhas na cultura de milho. Passo Fundo: Embrapa, 2006. 